\title{
ESA agrees full re-fly for Cluster mission
}

[MUNICH] The European Space Agency (ESA) last week decided to re-fly all four satellites of its Cluster mission. The original mission was destroyed when the Ariane V launcher exploded on its maiden flight in June last year (see Nature 381, 541; 1996).

Although the decision will strain ESA's already stretched budgets even further, its Science Programme Committee (SPC) felt this was justified by the scientific value of Cluster, which will measure the interactions between the solar wind and the Earth's magnetosphere.

The decision also represents recognition of the substantial development costs that ESA had invested in the original Cluster mission. But perhaps the most important factor was the relatively low cost of the relaunch. ESA has managed to keep the costs of Cluster 2 below the ceiling established for the rescue programme last year, chiefly by tough negotiations with contractors, but also by using a relatively cheap launcher, the Russian Soyuz.

The final price of ECU214 million (US $\$ 300$ million) also includes a significant contribution - around 40 per cent - from the agency towards the costs of rebuilding the scientific instruments, something normally shouldered entirely by participating member states. France, Germany and Britain, the three member states with the greatest interests in Cluster, had previously said they could not afford the full costs of

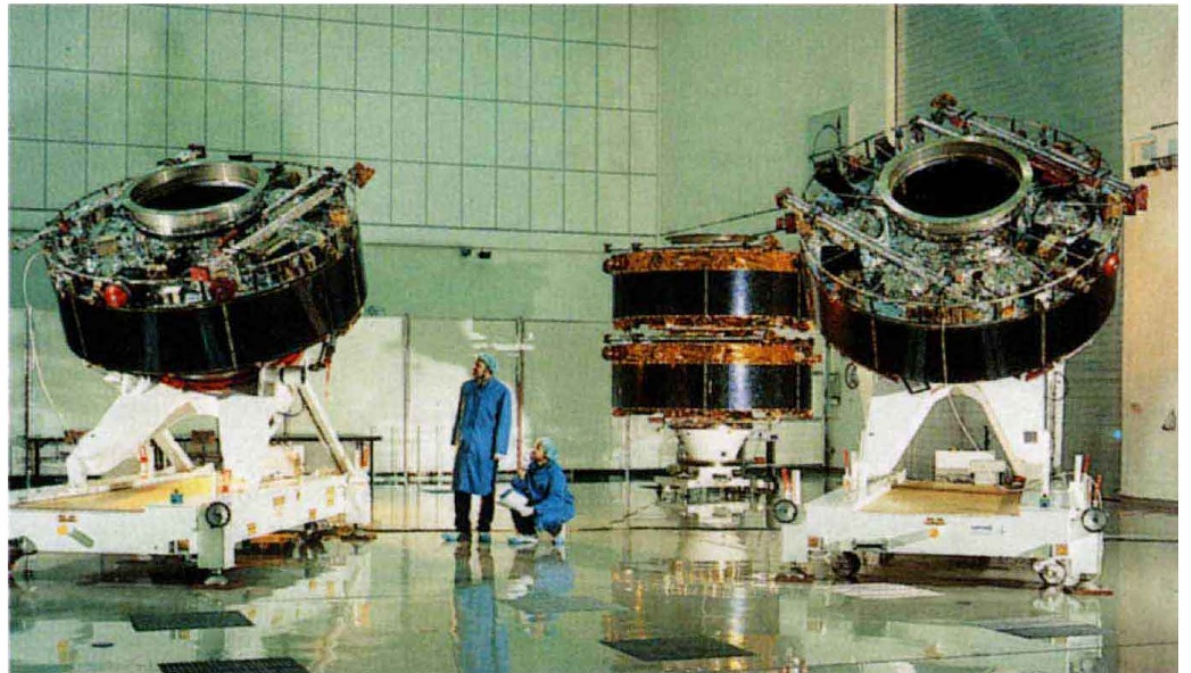

Twin peek: Cluster's satellites will get a second chance.

replacing the instruments, estimated to be around ECU40 million.

The German aerospace company Dornier will be the prime contractor for refurbishing the original Cluster mission's spare satellite - nicknamed Phoenix for the hope it gave that Cluster could rise from its own ashes - and for building three identical satellites. Cluster 2 will be launched in two pairs, on Soyuz launchers, in mid-2000.

The launch of all four satellites, rather than Phoenix alone, means Cluster will retain its unique ability to provide a three- dimensional analysis of the magnetosphere. But according to Giacomo Cavallo, head of science planning at ESA, some of Cluster's other aims may have to be adjusted.

The four-year delay means that Cluster 2 cannot be coordinated with other satellites that are now flying, such as the solar observatory SOHO run jointly by ESA and the US National Aeronautics and Space Administration, which may end its operations in 1998. But it does mean that it will be around when sunspot activity is at a peak, in 2001 and 2002.

Alison Abbott

\section{Europe outlines labelling rules for genetic modification seeds}

[MUNICH] Consumer and environmental organizations have gained some ground in the continuing controversy over the labelling of genetically-engineered products. Last week the European Commission approved an amendment to its directive on the deliberate release of genetically modified organisms to make it compulsory for genetically engineered seeds to be labelled as such.

But the new rule will not apply retrospectively. It will therefore not affect the dozen or so modified seeds already approved for sale in the European Union, including the controversial pest-resistant maize produced by Ciba (see Nature 384, 503; 1996). Nor will it necessarily apply to crops that have been grown from modified seeds or to processed foods that are based on such crops.

Greenpeace is unhappy with the new rule, which it argues is not tight enough, particularly because mixtures of modified and non-modified seeds would only need to carry a label saying the

\section{IMAGE UNAVAILABLE FOR COPYRIGHT REASONS}

Heights of protest? Greenpeace attached banners to the towers of Cologne cathedral.

mixture 'may contain' genetically modified organisms. More generally Greenpeace is unhappy about the gap between labelling at the agricultural and consumer levels. If tomato seeds were labelled as containing genetically modified organisms, this would not mean that tomato paste made from the products of such seeds would have to be similarly labelled, says a spokeswoman.
The commission's environment directorate sees the new rule as an interim measure, and is carrying out a complete review of the directive on deliberate release of genetically modified organisms. It intends to report to the Council of Ministers and the European Parliament in the next months on the comprehensive labelling of such organisms and their products.

The only other existing directive on genetically modified organisms is that concerning novel foods. This requires labelling of genetically modified foods only if they can be shown to have characteristics that clearly differ from their non-modified counterparts.

The environment directorate would like to see much tougher rules on labelling, and would like all steps in the food chain - from production on the farm to retail sales from the supermarket shelf - to be regulated. In contrast, the trade and industry directorates believe this to be too restrictive.

A. A. 